\title{
Congenital radial head dislocation with a progressive cubitus valgus: a case report
}

\author{
Laurens Kaas $\cdot$ Peter A. A. Struijs
}

Received: 9 June 2011 / Accepted: 20 December 2011/Published online: 6 January 2012

(C) The Author(s) 2012. This article is published with open access at Springerlink.com

\begin{abstract}
Congenital dislocation of the radial head is rare, although it is the most common congenital anomaly of the elbow. A concomitant progressive cubitus valgus of the elbow has not previously been described in literature. We describe a case of an 8-year-old girl with an unilateral congenital radial head dislocation with a progressive cubitus valgus of $35^{\circ}$, caused by a prematurely closing physis of the lateral humeral condyle. This might be caused by an increased pressure on the lateral physis by the anteriorly dislocated radial head. As no complaints or limitations were present, treatment was non-operative with clinical observation, with satisfactory results after a followup of 18 months. A concomitant progressive cubitus valgus can be present in patients with a congenital radial head dislocation. Non-operative treatment can provide satisfactory results.
\end{abstract}

Keywords Congenital radial head dislocation .

Cubitus valgus - Elbow - Anomaly · Treatment $\cdot$ Review

\section{Introduction}

Chronic radial head dislocation can be either congenital, developmental or post-traumatic $[1,2]$. Congenital dislocation of the radial head is rare, although it is the most common congenital anomaly of the elbow. It can occur

L. Kaas - P. A. A. Struijs

Department of Orthopaedic Surgery, Academic Medical Center,

Amsterdam, The Netherlands

L. Kaas $(\bowtie)$

Bethaniëplein 10, 3701 EM Zeist, The Netherlands

e-mail: laurenskaas@hotmail.com uni- and bilateral and has been described as an isolated abnormality, as well as a feature of a number of syndromes [3-5]. The diagnosis is often not made at birth, but when children present with limitation in range of motion (ROM), deformity of the elbow or elbow pain [2,3]. Dislocation is usually towards posterior (65\%) [2]. We present a case of an 8-year-old girl with unilateral congenital anterior radial head dislocation with a progressive cubitus valgus caused by a premature physeal closure or a growth arrest of the lateral humeral condyle. In girls, this growth plate normally closes at about the age of 12-8 years, with a range from 9-6 to 15-0 years. The physis of the medial epicondyle of girls closes at the age of $11-0$ to $16-0$ years, with a mean of 14-1 years [6]. Additionally, we review the literature on congenital dislocation of the radial head.

\section{Case report}

An 8-year-old girl with a rapidly increasing valgus angle of the right elbow presented at the out-patient clinic of our hospital. No evident trauma of the affected elbow had occurred. In another hospital, she had been diagnosed with a unilateral congenital radial head dislocation of the right elbow at the age of 3 months, for which a conservative treatment was initiated. Besides the increasing deformity, the patient had no complaints of pain or limitations. On physical examination, the patient was found to have a full and painless ROM and a normal carrying angle of the left elbow. The right elbow showed a cubitus valgus with clinically a carrying angle of $32^{\circ}$. The dislocated radial head was not painful on palpation. The range of motion was nearly full: flexion $130^{\circ}$, extension $10^{\circ}$, pronation $75^{\circ}$ and supination $80^{\circ}$, compared with a flexion of $140^{\circ}$, extension of $0^{\circ}$, pronation of $80^{\circ}$ and supination of $80^{\circ}$ of 
the contralateral elbow. Plain radiographic evaluation of the right elbow showed an anterior dislocation and deformation of the radial head, with a long narrow neck and a hypoplastic capitellum and an increased valgus angle (Figs. 1 and 2). The left elbow showed no abnormalities. Radiographs of both forearms show a mild ulnar bowing on the right side, as compared to the left side $\left(17\right.$ and $\left.12^{\circ}\right)$ (Figs. 3 and 4). This is probably due to chronic dislocation of the radial head. CT imaging of the elbow showed the anterior dislocation of the radial head with an overgrowth of the radius of $8 \mathrm{~mm}$ and a normal ulnohumeral joint. There is a premature ossifying physis of the lateral humeral condyle (Fig. 5). Whilst no complaints or limitations were present, treatment was non-operative with clinical observation. No restrictions in daily elbow use were advised. The result of this treatment strategy was satisfactory after a follow-up of 18 months. No increase in valgus angle was seen, and elbow function was not painful. Treatment of the valgus angle can be observational. In case of progression, a supracondylar varus osteotomy can be considered.

\section{Discussion}

To our best knowledge, the combination of congenital radial head dislocation and cubitus valgus has never been described in literature. Premature closure of the physis of the lateral condyle seems the cause on CT imaging. This growth arrest might have several causes, for example, trauma, infection, irradiation or bone tumours [7-9]. An altered physical pressure on the open physis can result in a stimulatory or inhibitory effect on growth and extreme forces can even fully inhibit growth. However, much milder forces can inhibit or modify the epiphyseal growth rate [6]. The capitellum generally becomes visible in the

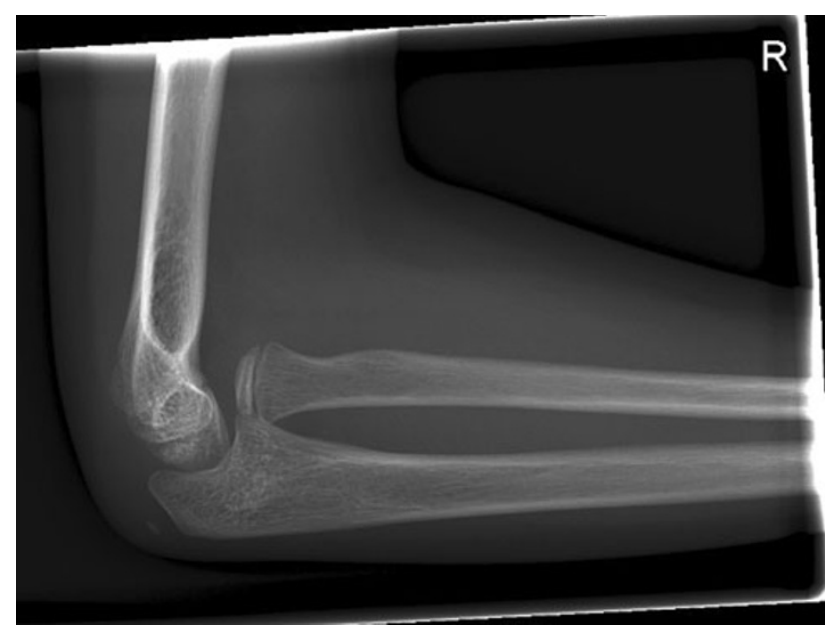

Fig. 1 Lateral radiograph of the patients' right elbow. Note the dislocation of the radial head first or second year of life. During maturation, the capitellum fuses with the trochlea and the lateral epicondyle, before it unites with the humeral shaft at a median age of $12-8$ years in girls, with a range from 9-6 to $15-0$ years

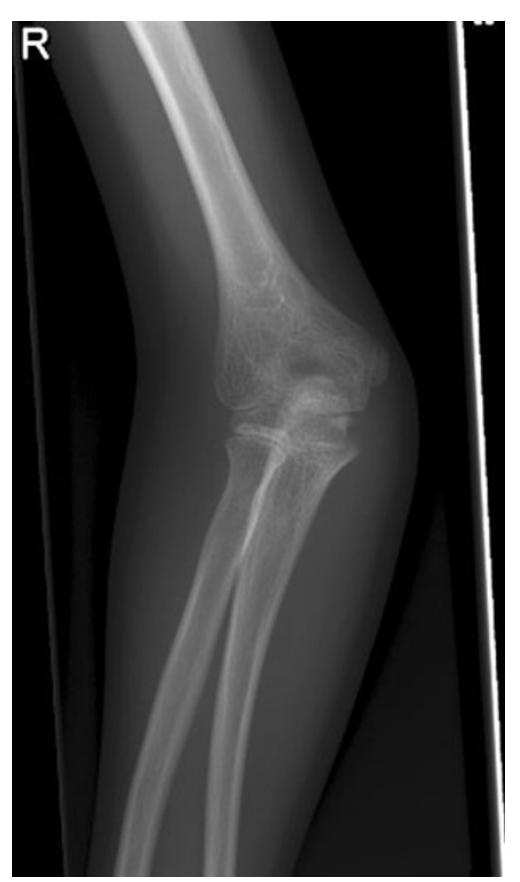

Fig. 2 Anteroposterior (AP) radiograph of the elbow. Note the valgus angle and the dislocation of the radial head

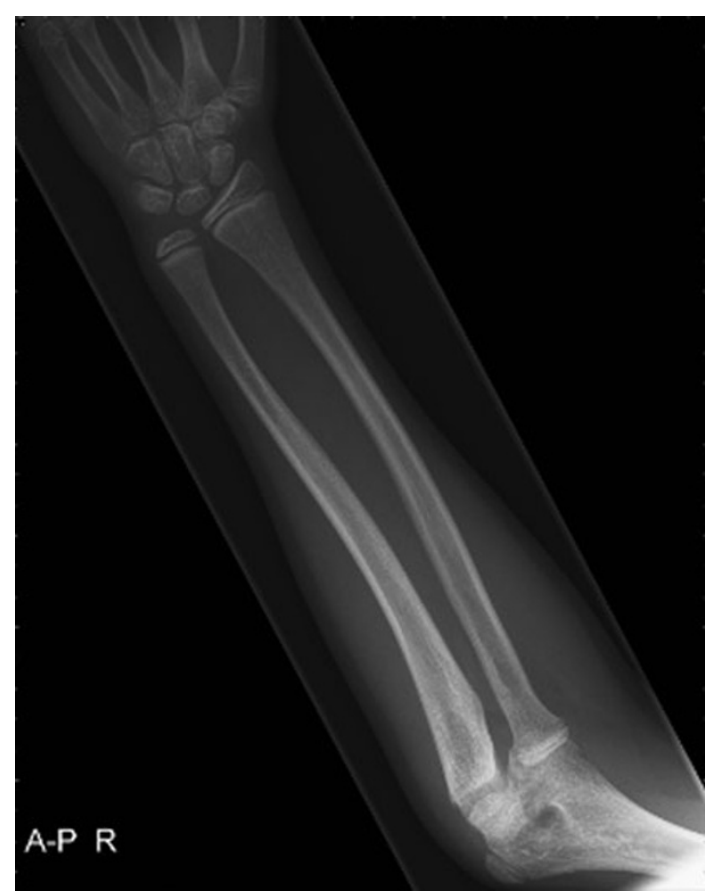

Fig. 3 AP radiograph of the right forearm. A mild bowing of the ulna can be observed 


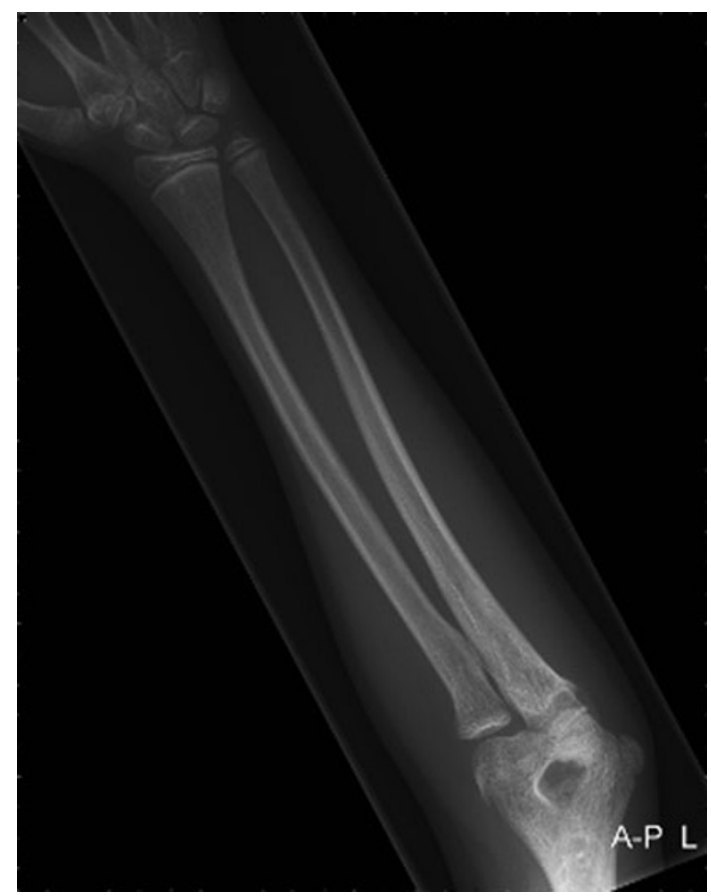

Fig. 4 AP radiograph of the unaffected left forearm

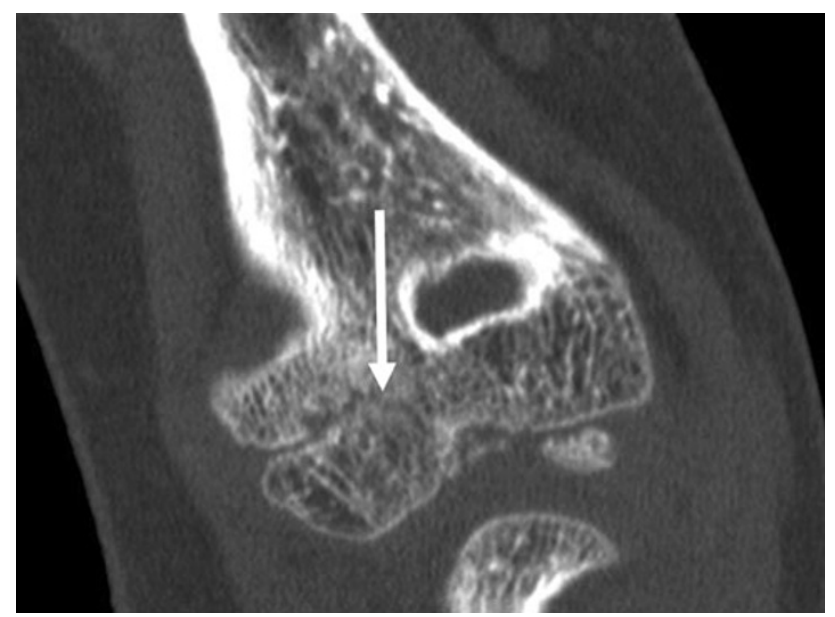

Fig. 5 Sagital view of the CT-scan of the patients' right elbow. The partially ossifying physis with boney bridges of the lateral humeral condyle is marked with an arrow

[6]. In our case, anterior dislocation and overgrowth of the proximal radius might have resulted in an increased pressure or repetitive minor trauma on the lateral physis, causing the growth arrest with an additional cubitus valgus, as a result of continuing growth of the medial epiphysis. An unnoticed trauma could also be the cause of the physeal growth arrest [6].

The effects of cubitus valgus can be function loss and cosmetic disturbance $[10,11]$. The goal of corrective surgery is restoration of alignment and range of motion. Indications for surgical intervention are similar to surgical correction of a cubitus varus deformity: functional limitation, elbow pain and cosmetic reasons. Several osteotomy techniques are described, such as closing wedge osteotomy, corrective dome osteotomy and step-cut osteotomy. Functional outcomes are generally good. Elbow stiffness, ulnar nerve injury and persistent deformities are the most commonly reported complications [12].

The exact cause of congenital radial head dislocation remains unknown. There have been reports of familial occurrence, but no definitive hereditary pattern has been established [3, 13-15]. Some believe that an abnormal capitellum formation in utero lays at the base of the disorder [2, 3, 5]. (Unrecognized) Trauma had also been stated to be the cause of radial head dislocations in newborn, especially if it occurs unilateral. A pulled elbow of infancy resulting in radial head (sub) luxation and laxity of the annular ligament may occur as shortly after birth. If not treated by closed reduction, persistent radial head dislocation may result in similar deformities as in children with a congenital radial head dislocation [1,3]. Developmental causes of radial head dislocation include an inadequate length of the radius and multiple hereditary osteochondromatosis [1].

A wide variety of reported clinical morphology of the proximal radius, ulna and distal humerus exists. The annular ligament can be normal [16], dysplastic [17] or absent [18]. Posterior dislocation is most common (65\%). Anterior dislocation occurs in $18 \%$ of the cases and lateral in $17 \%$ [2]. Radiographic diagnostic criteria as described by McFarland are (1) relative shortening of the ulna or overlength of the radius, (2) absence or hypoplasia of the capitellum, (3) grooving of the distal radius, (4) prominent ulnar epicondyle, (5) a partially defective trochlea and (6) a dome-shaped radial head with a long narrow neck [19]. Additional criteria that favour a congenital dislocation are described by Mardam-Bey and Ger: (1) bilateral involvement and concurrence of other congenital anomalies, (2) familial occurrence, (3) dislocation seen at birth and (4) no history of trauma [2]. Ulnar bowing has also been described as an additional criterium $[16,17]$.

As the symptoms in childhood are usually mild, observation is the standard treatment. However, occasional pain and functional limitations may be experienced $[5,13,20]$. Painful elbow snapping as a result of annular ligament interposition during flexion and extension also has been reported [21]. Some children develop increasing elbow pain during adolescence [16]. Surgery can be indicated because of pain, functional impairment, snapping or cosmetic reasons. Various surgical treatment possibilities have been discussed in literature, for example, resection, rotation osteotomy [13], ulnar osteotomy and reconstruction of the annular ligament [18]. Resection is advised in a symptomatic patient after reaching skeletal maturity, because of the 


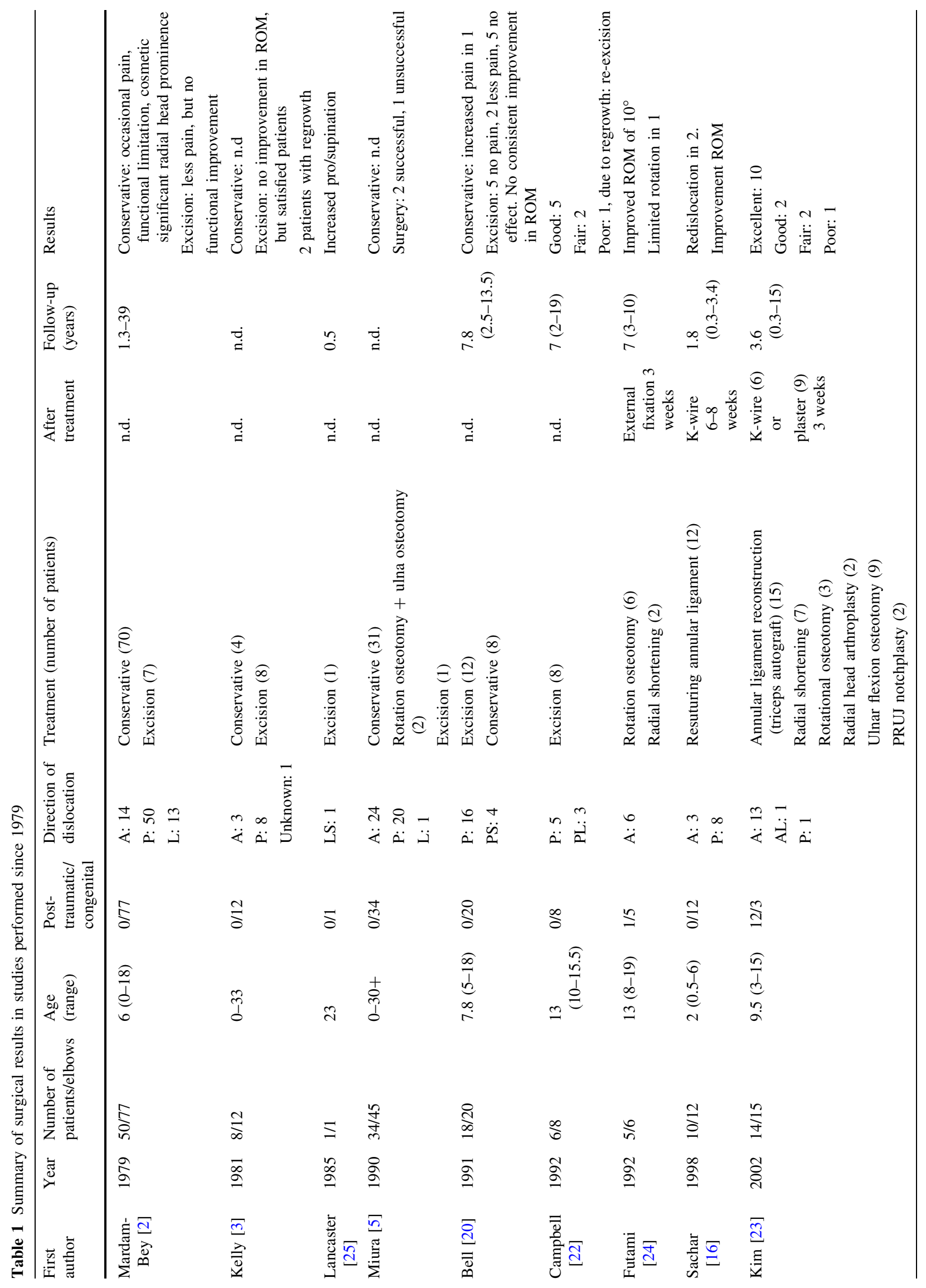


risk of regrowth if performed too early. Excision usually relieves pain, but does not always lead to significant functional improvement. Complications include pain in the distal radio-ulnar joint due to proximalization of the radius, instability, valgus deformation, weakness and regrowth of the proximal radius $[2,3,5,20,22]$. Open reduction, in combination with osteotomy of radius and/or ulna in younger patients is reported to be successful [17, 18, 23, 24]. To prevent redislocation in radial head sparing surgery, reconstruction of the annular ligament can be performed [16-18]. The results of surgical treatment of congenital radial head dislocations in literature since 1979 are summarized in Table 1. These publications consist of retrospective case reports or case series with a small numbers and heterogenous patient groups. No randomized comparison between surgical and conservative treatment has been made.

\section{Conclusion}

Congenital dislocation of the radial head is rare, although it is the most common congenital anomaly of the elbow. A concomitant progressive cubitus valgus can be present in patients with a congenital radial head dislocation. This might be caused by an increased pressure on the lateral physis by the anteriorly dislocated radial head or an unnoticed trauma. If no complaints or limitations are present, non-operative with clinical observation can lead to satisfactory results.

Conflict of interest The authors declare no conflict of interests.

Open Access This article is distributed under the terms of the Creative Commons Attribution License which permits any use, distribution and reproduction in any medium, provided the original author(s) and source are credited.

\section{References}

1. Amadio PC, Dobyns JH (2009) Congenital abnormalities of the elbow. In: Morrey BF, Sanchez-Sotelo J (eds) The elbow and its disorders. Saunders, Philadelphia, pp 184-205

2. Mardam-Bey T, Ger E (1979) Congenital radial head dislocation. J Hand Surg Am 4:316-320

3. Kelly DW (1981) Congenital dislocation of the radial head: spectrum and natural history. J Pediatr Orthop 1:295-298

4. Agnew DK, Davis RJ (1993) Congenital unilateral dislocation of the radial head. J Pediatr Orthop 13:526-528

5. Miura T (1990) Congenital dislocation of the radial head. J Hand Surg Br 15:477-481

6. Shapiro F (2001) Developmental bone biology. In: Shapiro F (ed) Pediatric orthopedic deformities. Academic Press, San Diego, pp 3-119

7. Peters W, Irving J, Letts M (1992) Long-term effects of neonatal bone and joint infection on adjacent growth plates. J Pediatr Orthop 12:806-810 
8. Peterson HA (2009) Physeal fractures of the elbow. In: Morrey BF, Sanchez-Sotelo J (eds) The elbow and its disorders. Saunders, Philadelphia, pp 246-267

9. Violas P, Salmeron F, Chapuis M, de Sales GJ, Bracq H, Cahuzac JP (2004) Simple bone cysts of the proximal humerus complicated with growth arrest. Acta Orthop Belg 70:166-170

10. De Boeck H, De Smet P (1997) Valgus deformity following supracondylar elbow fractures in children. Acta Orthop Belg 63:240-244

11. Langenskiöld A, Kivilaakso P (1967) Varus and valgus deformitiey of the elbow following supracondylar fracture of the humerus. Acta Orthop Scand 38:313-320

12. Shaggs DL, Flynn JM (2009) Supracondylar fractures of the distal humerus. In: Beaty JH, Kasser JR (eds) Rockwood and Wilkins' fractures in children. Lippincott, Williams \& Wilkins, Philadelphia, pp 487-532

13. Echtler B, Burckhardt A (1997) Isolated congenital dislocation of the radial head. Good function in 4 untreated patients after 14-45 years. Acta Orthop Scand 68:598-600

14. Reichenbach H, Hormann D, Theile H (1995) Hereditary congenital posterior dislocation of radial heads. Am J Med Genet 55:101-104

15. Gattey PH, Wedge JH (1986) Unilateral posterior dislocation of the radial head in identical twins. J Pediatr Orthop 6:220-221

16. Sachar K, Mih AD (1998) Congenital radial head dislocations. Hand Clin 14:39-47

17. Kim HT, Conjares JN, Suh JT, Yoo CI (2002) Chronic radial head dislocation in children, Part 1: pathologic changes preventing stable reduction and surgical correction. J Pediatr Orthop 22:583-590

18. Yamazaki H, Kato H (2007) Open reduction of the radial head with ulnar osteotomy and annular ligament reconstruction for bilateral congenital radial head dislocation: a case with long-term follow-up. J Hand Surg Eur Vol 32:93-97

19. McFarland B (1936) Congenital dislocation of the radial head of the radius. Br J Surg 24:41-49

20. Bell SN, Morrey BF, Bianco AJ (1991) Chronic posterior subluxation and dislocation of the radial head. J Bone Joint Surg Am 73:392-396

21. Maruyama M, Takahara M, Kikuchi N, Ito K, Watanabe T, Ogino T (2010) Snapping elbow with congenital radial head dislocation: case report. J Hand Surg Am 35:981-985

22. Campbell CC, Waters PM, Emans JB (1992) Excision of the radial head for congenital dislocation. J Bone Joint Surg Am 74:726-733

23. Kim HT, Park BG, Suh JT, Yoo CI (2002) Chronic radial head dislocation in children, Part 2: results of open treatment and factors affecting final outcome. J Pediatr Orthop 2:591-597

24. Futami T, Tsukamoto Y, Fujita T (1992) Rotation osteotomy for dislocation of the radial head. 6 cases followed for 7 (3-10) years. Acta Orthop Scand 63:455-456

25. Lancaster S, Horowitz M (1987) Lateral idiopathic subluxation of the radial head. Case report. Clin Orthop Relat Res 214:170-174 